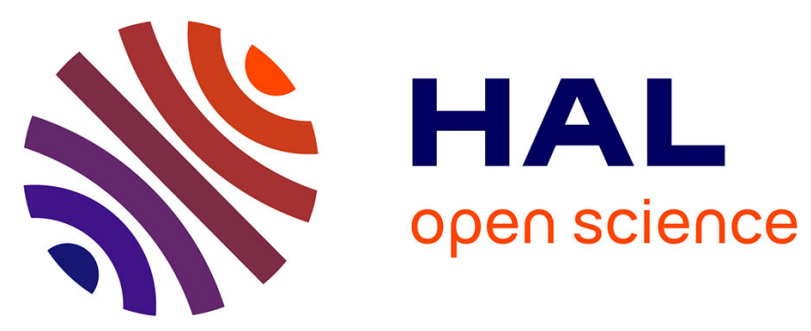

\title{
Ferroelectric tunability: from characterization to telecomunication application
}

\author{
Hartmut Gundel, Raphaël Renoud, Caroline Borderon, Sabrina Pavy, Ala \\ Sharaiha, Viet Hung Nguyen, Ratiba Benzerga, Christophe Delaveaud
}

\section{- To cite this version:}

Hartmut Gundel, Raphaël Renoud, Caroline Borderon, Sabrina Pavy, Ala Sharaiha, et al.. Ferroelectric tunability: from characterization to telecomunication application. ISAF International Symposium on Applications of Ferroelectrics, Jul 2012, Aveiro, Portugal. hal-00749728

\section{HAL Id: hal-00749728 \\ https://hal.science/hal-00749728}

Submitted on 8 Nov 2012

HAL is a multi-disciplinary open access archive for the deposit and dissemination of scientific research documents, whether they are published or not. The documents may come from teaching and research institutions in France or abroad, or from public or private research centers.
L'archive ouverte pluridisciplinaire HAL, est destinée au dépôt et à la diffusion de documents scientifiques de niveau recherche, publiés ou non, émanant des établissements d'enseignement et de recherche français ou étrangers, des laboratoires publics ou privés. 


\section{Ferroelectric tunability: from characterization to telecomunication application}

\author{
Hartmut W. GUNDEL, Raphaël RENOUD, \\ Caroline BORDERON, Sabrina PAVY \\ LUNAM Université \\ IETR UMR 6164 \\ UFR Sciences Nantes, 2 rue de la Houssinière \\ 44322 Nantes, France
}

\author{
Ala SHARAIHA, Viet Hung NGUYEN, \\ Ratiba BENZERGA \\ IETR UMR 6164, Université de Rennes1 \\ Campus de Beaulieu, 35042 Rennes, France \\ Christoph DELAVEAUD \\ CEA / Léti, 38054 Grenoble, France
}

\begin{abstract}
Advanced dielectric spectroscopy enables studying of the ferroelectric complex permittivity. Interpretation with the hyperbolic law provides a better fundamental understanding of the material's tunability: bulk contribution, domain wall vibration and displacements may be discerned. Applications, like mobile telecommunication terminals may profit for the design of miniaturized and tunable antennas. As an example, conception and realization of a notch slot antenna with an integrated ferroelectric thin film varactor is presented.
\end{abstract}

Keywords-ferroelectrics; thin films; dielectric spectroscopy; tunability; antenna; telecommunication application; BST

\section{INTRODUCTION}

The still growing demand to integrate more applications in mobile communication terminals comes along with the need to cover an increasingly larger frequency band, as these services are subjected to different standards. After miniaturization, electronic tunability hence becomes a main research issue since this will allow reducing the number of components in the terminal. Multifunctional ferroelectric thin films offer both, the possibility of miniaturization due to the material's high-k character and tunability due to the non-linear characteristic between the electric field and the material's polarization.

While bulk ferroelectrics have already been used for size reduction since a long time, the study and application of the tunable ferroelectric permittivity is still at the beginning. Two main problems, one concerning fundamental research issues, the other being of technological origin, have to be resolved. Firstly, amelioration of the ferroelectric dielectric properties (losses and tunability) as well as material characterization is rather demanding especially at microwave frequencies and in the case of high-k thin films. Secondly, proper application needs the use of low cost substrates and reliable technologies that guarantee large areas homogeneous dielectric properties; in addition, thin film integration should be possible.

In the present paper, we discuss an advanced dielectric spectroscopy method, based on the interpretation of the hyperbolic law [1, 2], antenna conception related issues, and present an approach for a tunable antenna with the use of $\mathrm{BaSrTiO}_{3}$ (BST) ferroelectric thin film [3].

\section{DIELECTRIC SPECTROSCOPY OF FERROELECTRIC THIN FILMS}

The complex dielectric permittivity of displacive type ferroelectrics is related to the material's microscopic properties (bulk contribution) as well as to the existence of macroscopic domain wall motion and is strongly frequency dependent. While today's telecommunication applications mainly use frequencies in the UHF band and up to the X-band (8 to 12 $\mathrm{GHz}$ ), tunability of the dielectric permittivity also implies DC biasing of the material $(\omega=0)$. Dielectric spectroscopy thus has to cover a large frequency range. Low frequency characterization allows studying diffusion and domain wall relaxation that will be helpful for reducing dielectric losses. High frequency ferroelectric properties need to be known for the conception of the particular telecommunication device.

a)

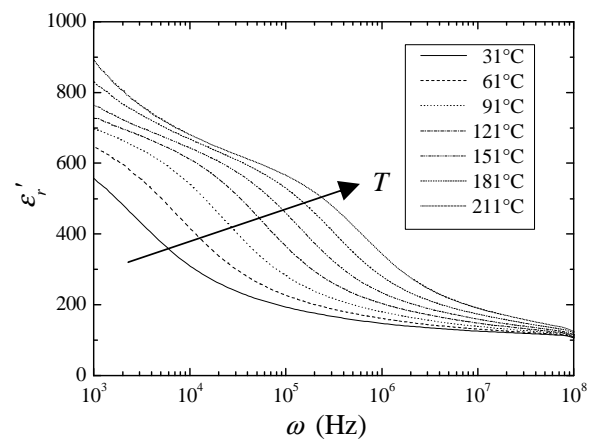

b)

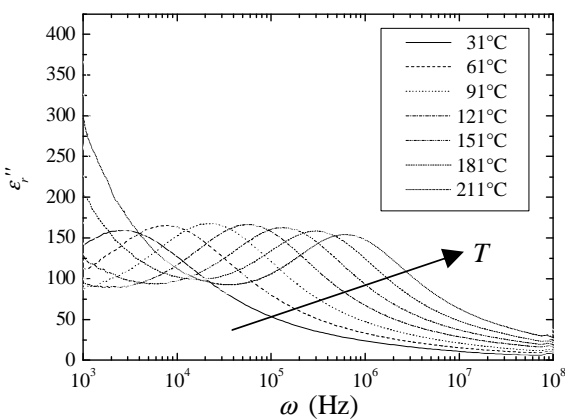

Figure 1. Real part $\varepsilon_{\mathrm{r}}^{\prime}$ (a) and imaginary part $\varepsilon_{\mathrm{r}}$ " (b) of the complex dielectric permittivity of $\mathrm{Ba}_{0.90} \mathrm{Sr}_{0.10} \mathrm{TiO}_{3}$ thin films dopes with $1 \%$ manganese as a function of frequency and at different temperatures. 
Figure 1 shows typical results of the frequency dependent complex permittivity of a $\mathrm{Ba}_{0.90} \mathrm{Sr}_{0.10} \mathrm{TiO}_{3}$ thin film doped with $1 \%$ manganese as a function of frequency and at different temperatures.

The inflexion point of each permittivity curve (Fig. 1a) corresponds to a maximum of the dielectric losses curve (Fig. 1b), respectively, indicating for each temperature the domain wall relaxation frequency [2]. The diffusion phenomenon may be better discerned in the Argand representation of Fig. 2, well visible by the straight line at the low frequency side of the diagram.

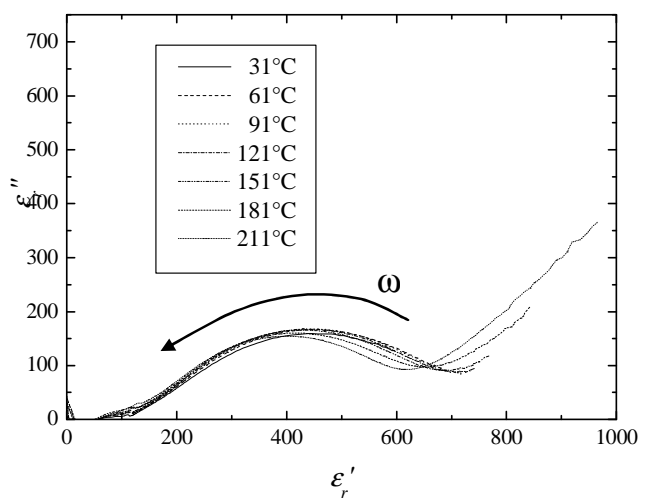

Figure 2. Argand diagramm representation ( $\varepsilon_{\mathrm{r}}$ "' vs $\varepsilon_{\mathrm{r}}$ ') of $\mathrm{Ba}_{0.90} \mathrm{Sr}_{0.10} \mathrm{TiO}_{3}$ thin films dopes with $1 \%$ manganese for different temperatures.

Reducing diffusion is especially important when static electric fields are needed as it is in the case of the DC tunability of the ferroelectric permittivity. The influence of manganese doping of $\mathrm{Ba}_{0,80} \mathrm{Sr}_{0,20} \mathrm{TiO}_{3}$ thin films realized on stainless steel substrates by Chemical Solution Deposition (CSD) has been shown recently [4]. Dielectric characterization as a function of frequency showed that doping had only little influence on the domain wall relaxation frequency. The Argand diagrams, however, revealed that low frequency diffusion is considerably affected. Oxygen vacancies are the most important defects that generate conduction in ferroelectric perovskites. The dielectric losses hence are directly influenced by doping (in this case $\mathrm{Mn}^{2+}$ acceptor doping). This is especially true in the case of CSD synthesis on steel substrates where the creation of oxygen vacancies in the films is favored due to substrate oxidation during the necessary high temperature crystallization process.

The ferroelectric relative complex permittivity also depends on the excitation field strength $E_{0}$ and can be described by the hyperbolic law [1]:

$$
\varepsilon_{r}=\varepsilon_{r l}+\sqrt{\varepsilon_{r-r e v}^{2}+\left(\alpha_{r} E_{0}\right)^{2}} .
$$

$\varepsilon_{r l}$ is the intrinsic lattice polarization part to which two domain wall contributions have to be added: reversible domain wall vibrations (coefficient $\varepsilon_{r-\text { rev }}$ ), and irreversible domain wall displacements, with $\alpha_{r}$ the parameter identical to that used in the linear Rayleigh approach. The general behavior of the hyperbolic law is shown in Fig. 3 allowing distinguishing the different contributions to the ferroelectric permittivity.

Examination of the hyperbolic law also allows identifying the different characteristic relaxation times [2]. In the case of
$\mathrm{Pb}\left(\mathrm{Zr}_{0.43} \mathrm{Ti}_{0.57}\right) \mathrm{O}_{3}$ thin films, bulk relaxation was observed at approximately $10 \mathrm{kHz}$, while reversible and irreversible domain wall motion had lower relaxation frequencies around $1 \mathrm{kHz}$.

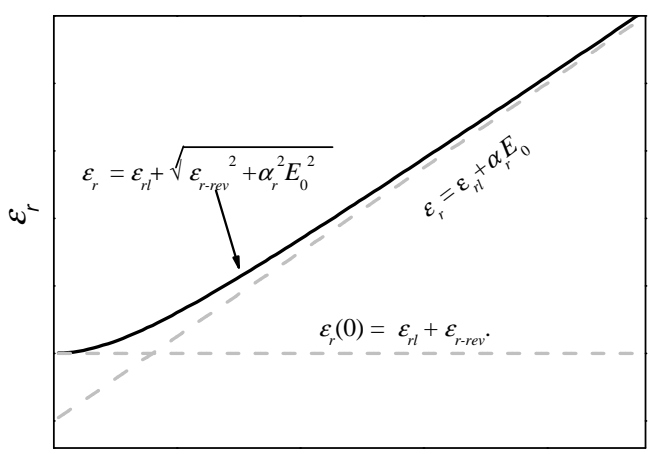

Field amplitude $E_{0}$

Figure 3. Variation of the ferroelectric relative permittivity $\varepsilon_{\mathrm{r}}$ as a function of the ac excitation field $E_{0}$.

A further interesting feature results from the possibility to discriminate the different parts of the material's tunability [5]. While the intrinsic lattice polarization largely dominates the global ferroelectric permittivity and domains present only a minor role, the contribution of domain wall vibrations and displacements to the material's tunability is rather important. This comes along with the significant variation of the domain wall density which vanishes when the bias electric field causes saturation.

The high frequency complex ferroelectric permittivity may be determined either in a co-planar transmission line or in a metal-insulator-metal (MIM) geometry depending on the type of substrate used for the deposition of the thin films. Transmission line measurements are necessary in the case of an insulating substrate; however, most often they suffer from a rather low precision. This is due to the need to deduce the thin film permittivity from the measured effective permittivity value taking also into account the substrate which, in general, is much thicker than the ferroelectric layer but has a considerably lower dielectric constant. Determination of the transmission parameter $S_{11}$, in addition, is adapted for a distinct frequency. Using MIM geometry, on the contrary, offers the advantage of continuous frequency measurements. In both cases, it is important to remember that a change of the substrate will also affect the crystallization behavior of the ferroelectric and hence its dielectric properties.

A typical MIM geometry, allowing a frequency dependent measurement of the complex dielectric permittivity up to the $\mathrm{GHz}$ region, is shown in Fig. 4 [6].
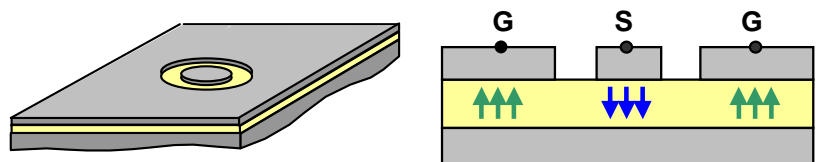

Figure 4. MIM geometry for GSG measurements of the complex dielectric permittivity of thin film ferroelectrics. 
The relative permittivity and the dielectric losses $\tan \delta$ of $\mathrm{PbZr}_{0.57} \mathrm{Ti}_{0.43} \mathrm{O}_{3}$ are shown in Fig. 5 as a function of frequency [6]. The continuity between the results of the classic impedance bridge measurements below $10 \mathrm{MHz}$ and these obtained at higher frequencies with an network analyzer, proves the validity of this latter method.

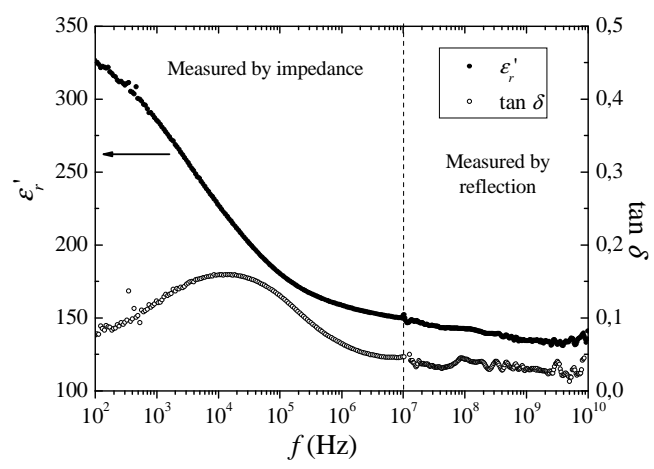

Figure 5. Dielectric permittivity $\varepsilon_{\mathrm{r}}$ ' and losses $\tan \delta$ as a function of frequency of a $\mathrm{PbZr}_{0.57} \mathrm{Ti}_{0.43} \mathrm{O}_{3}$ thin film.

The dielectric tunability (measured up to $1 \mathrm{MHz}$ ) can be extrapolated to higher frequencies using the Davidson-Cole model, which fits very well the experimental data of Fig. 2. The evolution of the tunability of a $\mathrm{Ba}_{0.80} \mathrm{Sr}_{0.20} \mathrm{TiO}_{3}$ thin film is shown in Fig. 6 where a slight decrease around a mean value of $25 \%$ can be seen in the UHF region. As domain wall relaxation already appears in the $10 \mathrm{kHz}$ region, the evolution of the thin film tunability may be considered continuous up to frequencies where ion resonance phenomena appear.

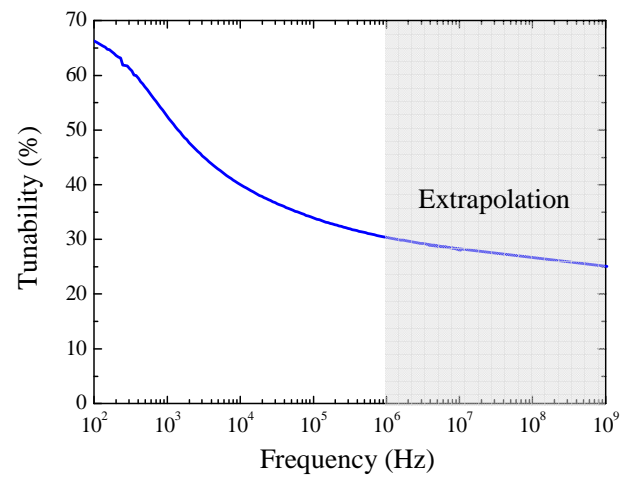

Figure 6. Etrapolation to the UHF frequency region of the tunability of $\mathrm{Ba}_{0.80} \mathrm{Sr}_{0.20} \mathrm{TiO}_{3}$ thin films.

\section{ANTENNA CONCEPTION}

Electrically small antennas that are frequency tunable allow the antenna to increase the operational bandwidth and to cover multiple applications while fitting within a small package. Most often varactor diodes are studied for tuning planar antennas. For example, a $3 \mathrm{GHz}$ - folded slot - antenna with varactors has been reported in [7] with a miniaturization of $30 \%$ and a tunablity of $5 \%$. A varactor tuned microstrip patch antenna has also been reported in [8]. In this case, the antenna has a center frequency of $2.13 \mathrm{GHz}$ and a tunablity of $10 \%$ under a DC bias voltage of $10 \mathrm{~V}$. In the present work, we report on a notch slot antenna with an integrated BST thin film varactor which is used for antenna miniaturization and reconfiguration [3]. A schematic cross section view of this antenna is shown in Fig. 7a. It is based on the use of an alumina substrate which serves as the support for the deposition of the BST thin film and backside antenna feed line. The top view (Fig. 7b) shows the antenna slot and the position of the feed line which is extended beyond the notch in order to realize $50 \Omega$ impedance matching. Two blocking capacitors allow applying the DC bias electric field necessary for polarizing the BST capacitor.

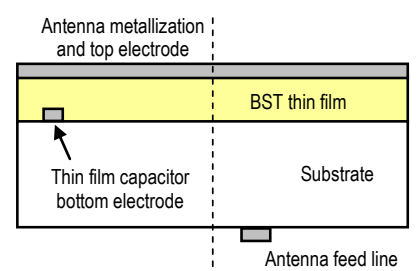

(a)

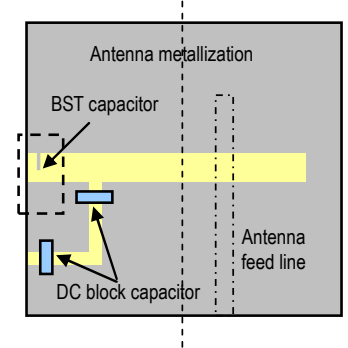

(b)
Figure 7. Schematic cross section view (a) and top view (b) of the BST thin film notch antenna.

The antenna has been simulated with the commercial software Ansys HFSS v13. Its geometry has been optimized for an antenna frequency of $1 \mathrm{GHz}$; the overall antenna surface was $20 \times 20 \mathrm{~mm}^{2}$. A dielectric relative permittivity of 95 , dielectric losses of $\tan \delta \approx 10^{-2}$, and a BST tunability of $30 \%$ at the maximum DC bias electric field have been supposed.

Without the BST ferroelectric thin film, the antenna frequency is $2.2 \mathrm{GHz}$. A size reduction of approximately $56 \%$ hence has been achieved. The antenna frequency tuning from $0.94 \mathrm{GHz}$ to $1.07 \mathrm{GHz}$, corresponding to a tunablity of $13 \%$, is shown in Fig. 8.

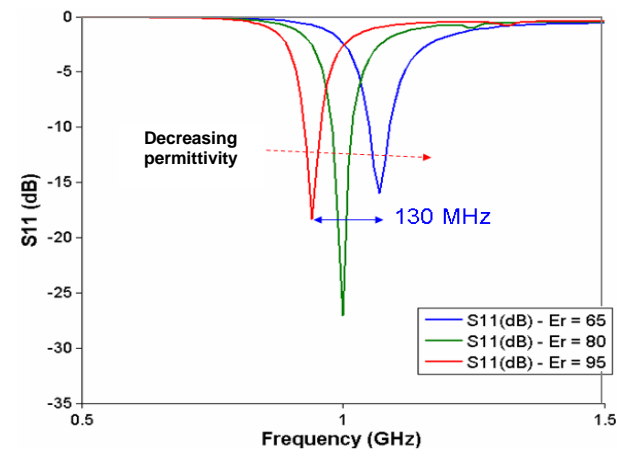

Figure 8. Return loss simulation of the antenna vs frequency for different dielectric permittivity of the BST thin film.

\section{BST THIN FILM INTEGRATION}

The detail of the tunable BST capacitor (cf. Fig. 7b) is shown in Fig. 9. Elaboration has been obtained by successive deposition onto the alumina substrate of a platinum bottom electrode, synthesis of the BST thin film by CSD [9], wet 
chemical etching of the ferroelectric layer [10] in order to realize the via, and finally deposition of the top electrode, which also establishes the radiating antenna surface.

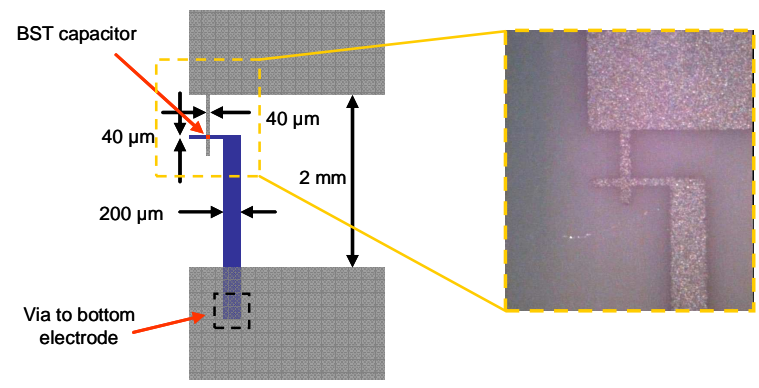

Figure 9. Detail of the ferroelectric capacitor.

The tunability of the integrated BST varactor can be found from the capacity - frequency diagram of Fig. 10. At the maximum DC bias voltage of $30 \mathrm{~V}$, corresponding to an electric field of approximately $450 \mathrm{kV} / \mathrm{cm}$, the $1 \mathrm{MHz}$ tunability $\left(C_{0}-C_{\mathrm{Umax}}\right) / C_{0}$ is approximately $30 \%$.

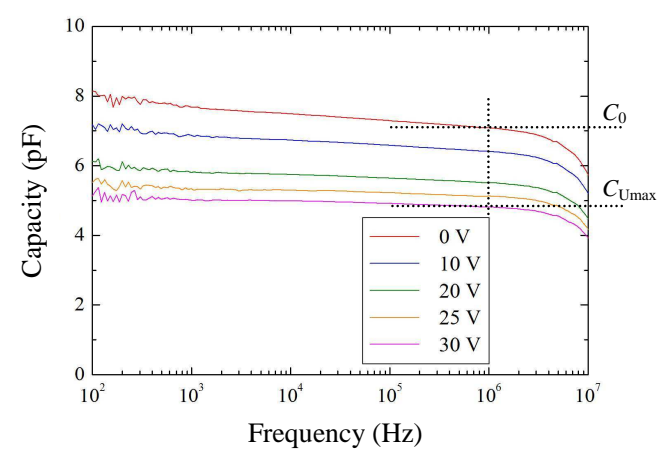

Figure 10. Capacity - frequency dependency of the integrated BST varactor for different DC bias voltage.

The rapid decay of the measured capacity at frequencies above several $\mathrm{MHz}$ is artificial and only due to the frequency limitation of the measurement method used. The dielectric losses at $1 \mathrm{MHz}$ are approximately $1 \cdot 10^{-2}$. The finalized antenna, mounted on a SMA coaxial connector, is shown in Fig. 11.

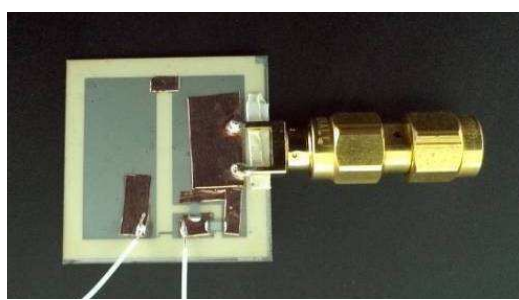

Figure 11. Slot antenna with integrated BST thin film.

Antenna characterization has not yet been performed.

\section{CONCLUSIONS}

Dielectric spectroscopy, and more particularly studying of the hyperbolic law, permit determination of the different contributions to the ferroelectric complex permittivity and hence allow optimization of the material. This is particular interesting for reducing diffusion, as low frequency losses are harmful to the tunability of the thin films.

$\mathrm{BaSrTiO}_{3}$ thin films can be conveniently elaborated on low cost alumina substrates by chemical solution deposition. It has been shown that the films exhibit dielectric loss values $\tan \delta$ of $1 \cdot 10^{-2}$, a $1 \mathrm{MHz}$ tunability of $30 \%$, and a dielectric breakdown strength above $450 \mathrm{kV} / \mathrm{cm}$. Extrapolation, using the DavidsonCole formalism, allow to estimate the tunabilty in the UHF frequency range to approximately $25 \%$.

Integration of the BST thin films into a notch slot antenna has been realized by conventional photolithography techniques. Antenna conception may profit from the high-k character of the ferroelectric and its non-constant permittivity for antenna miniaturization and tunability, respectively. Antenna characterization still has to be performed in order to prove the antenna concept.

\section{ACKNOWLEDGMENT}

The authors wish to acknowledge the contributions of F. Rortais and A. Renaud to the study of the BST thin films and the realization of the tunable antenna.

\section{REFERENCES}

[1] C. Borderon, R. Renoud, M. Ragheb, and H.W.Gundel, "Description of the low field nonlinear dielectric properties of ferroelectric and multiferroic materials", Appl. Phys. Lett. 98, 112903, 2011

[2] R. Renoud, C. Borderon, and H.W.Gundel, "Measurement and modeling of dielectric properties of $\mathrm{Pb}(\mathrm{Zr}, \mathrm{Ti}) \mathrm{O}_{3}$ ferroelectric thin films", IEEE Trans. Ultrasonics, Ferroelectrics, Frequency Control 58, 2011, pp.19751980.

[3] V. H. Nguyen, C. Borderon, R. Benzerga, Ch. Delaveaud, A. Sharaiha, and H.W. Gundel, "Miniaturized and reconfigurable notch antennas using a BST thin film varactor", Proc. IEEE International Symposium on Antennas and Propagation, July 8-14, 2012, Chicago, IL, USA.

[4] C. Borderon, R. Renoud , H.W. Gundel, "The effect of Mn doping on the dielectric properties and domain wall mobility of $\left(\mathrm{Ba}_{0.8} \mathrm{Sr}_{0.2}\right) \mathrm{TiO}_{3}$ thin films", Proc. ISIF 2011, July 31 to August 4, Cambridge, England.

[5] R. Renoud, C. Borderon, M. Ragheb, H.W. Gundel, "Matériaux ferroélectriques dans les dispositifs hyperfréquences: quelles caractérisations? ", Proc. 12èmes Journées de Caractérisation Microondes et Matériaux, Chambéry, France, march 28-30, 2012 (in French).

[6] C. Borderon, D. Averty, R. Renoud, H.W. Gundel, "Caractérisation diélectrique de couches minces de PZT, Proc. 11èmes Journées de Caractérisation Microondes et Matériaux", Brest, France, march 31 april 2, 2010 (in French).

[7] M. C. Scardelletti, G. E. Ponchak, J. L. Jordan, N. Jastram, and J. V. Mahaffey, "Tunable reduced size planar folded slot antenna utilizing varactor diodes," 2010 IEEE Radio and Wireless Symposium (RWS), 2010, pp.547-550.

[8] S. H. Al-Charchafchi and J. Kyriopoulos, "A varactor tuned microstrip patch antenna," in Antennas and Propagation, 1995, Ninth International Conference on Antennas and Propagation (Conf. Publ. No. 407), vol.1, 1995, pp.278-281.

[9] C. Borderon, "Developpement et etude des materiaux ferroelectriques accordables en vue d'une application pour les antennes intelligentes", Ph.D. thesis, University of Nantes, 2008 (in French).

[10] S. Pavy, S. Baron, C. Borderon, H.W. Gundel, "Wet chemical etching of BaSrTiO3 ferroelectric thin films for intelligent antenna applications", Proc. ISIF 2011, July 31 - August 4, Cambridge, England 